\title{
A Case of Nasal Chondromesenchymal Hamartoma Misunderstood as a Sphenochoanal Polyp in an Adult
}

\author{
Jang-Won Choi, $\mathrm{MD}^{1}$, Sang-Min Kim, $\mathrm{MD}^{1}$, Ji-Yeon Kim, $\mathrm{MD}^{2}$ and Yong-Wan Kim, $\mathrm{MD}, \mathrm{PhD}^{1}$ \\ ${ }^{1}$ Department of Otorhinolaryngology, ${ }^{2}$ Pathology, Inje University Haeundae Paik Hospital, Busan, Korea
}

\begin{abstract}
- ABSTRACT -
Nasal chondromesenchymal hamartoma $(\mathrm{NCMH})$ is a rare example of hamartoma and mainly involves the nose and paranasal sinuses. We report a case of NCMH in a 24-year-old Asian adult, which was misunderstood as a sphenochoanal polyp. Endoscopic examination showed the nasal passages were obstructed with a polypoid mass originated from left posterior ethmoid and sphenoidal sinus. Computed tomography (CT) demonstrated non-enhancing bulging soft masses. The patient underwent left endoscopic sinus surgery and resection of left sphenochoanal polypoid mass. Histopathology showed an inflammatory polyp with chondroid metaplasia. After 18 months, the patient visited the hospital again with a recurred polypoid mass at the same area. Revision endoscopic sinus surgery was performed. Finally, based on the histologic findings and results of immunohistochemistry, the nasal polyp was diagnosed as chondromesenchymal hamartoma. In the case of chondroid proliferations of the nose and paranasal sinuses, NCMH should be considered a differential diagnosis. (J Clinical Otolaryngol 2017;28:238-242)
\end{abstract}

KEY WORDS : Nasal neoplasms $\cdot$ Sphenoid sinus.

\section{Introduction}

A hamartoma can be defined as a focal malformation resembling a neoplasm, composed of an overgrowth of mature cells and tissues that normally occur in the affected area. Nasal chondromesenchymal hamartoma (NCMH) is a particularly uncommon example of a hamartoma and mainly involves the nose and paranasal sinuses. ${ }^{1)}$

Previous studies have reported only 30 cases in the international literature. ${ }^{2-4)}$ Though the most of the patients are in the first year of life, the disease has been found in adolescents and comparable adults. ${ }^{5)}$ Only

논문접수일 : 2017년 1월 12일

논문수정일 : 2017년 5월 23일

심사완료일 : 2017년 11월 13일

교신저자 : 김용완, 48108 부산광역시 해운대구 해운대로 875

인제대학교 의과대학 해운대백병원 이비인후과학교실

전화 : (051) 797-2290·전송 : (051) 797-2304

E-mail:kimyw@paik.ac.kr patient of the eight people are adolescents and adults. Age spread was in the range of between 16 to 69 years. $\mathrm{NCMH}$ shows a good prognosis and the histological appearance of benign in general. However, there was one case showing the potentiality of malignant changes in adult $\mathrm{NCMH}$ patient. According to the report, careful histological examination to differentiate tumors in adults is recommended. ${ }^{3)}$

\section{Case Report}

A 24-year-old Asian male visited our department complaining of nasal obstruction for 3 weeks. He had a hyperthyroidism being treated with oral antithyroidal agents.

The patient reported normal olfactory sensation, and facial sensation. He had no ophthalmological complaints.

On physical examination, the nasal passages were obstructed with polypoid masses originated left posterior ethmoid sinuses and sphenoidal sinus (Fig. 1). No 
enlargement of the cervical lymph nodes was discovered. Treatment with steroids, antibiotics was not effective. Computed tomography (CT) scans of the sinuses demonstrated a non-enhancing bulging soft polypoid mass in the left posterior ethmoid and sphenoid sinuses without the erosion of the sella turcica or adjacent bony wall invasion (Fig. 2).

The patient underwent functional endoscopic sinus surgery and resection of the left sphenochoanal

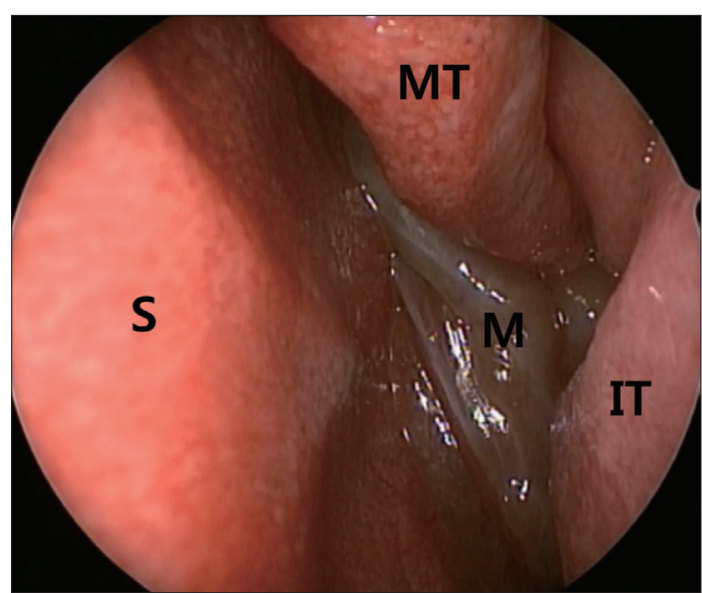

Fig. 1. Endoscopic finding shows that the nasal passage was obstructed with polypoid masses originated left posterior ethmoid sinuses and sphenoidal sinus. IT : inferior turbinate, $M T$ : middle turbinate, $S$ : septum, $M$ : mass. polyp without further imaging. Intraoperatively, a polyp showed non-pedunculated and simultaneous attachment to multiple walls, mainly from the floor and lateral wall of left sphenoid sinus septum. The polyp showed grossly pinkish gray soft mass with polypoid change. Immunohistochemical staining was positive at S100. Histological diagnosis was inflammatory polyp with chondroid metaplasia.

After 18 months, the patient revisited the hospital with a polypoid mass in the same area. Revision endoscopic sinus surgery was performed. Authors meticulously removed it as radically as possible. All gross masses was eventually removed with surrounding normal mucosa and attachment sites were drilled out (Fig. 3).

Similarly the polyp was grossly grayish white soft tissue with areas of cartilage. Histologically, the excised nasal polyp was composed of intact sinonasal epithelium with subepithelial sheets of spindle cells and islands of cartilage. The spindle cells comprised compact hypercellular bands, abutting the sinonasal epithelial surface. At high power microscopic view, the spindle cells exhibited bland cytologic features with minimal pleomorphism and scanty mitoses. Immunohistochemically, the cells were positive for vimentin, a kind of intermediate filament expressed in mesenchymal cells. The cartilaginous nodules were scattered within myxoid stroma and occasionally surrounded
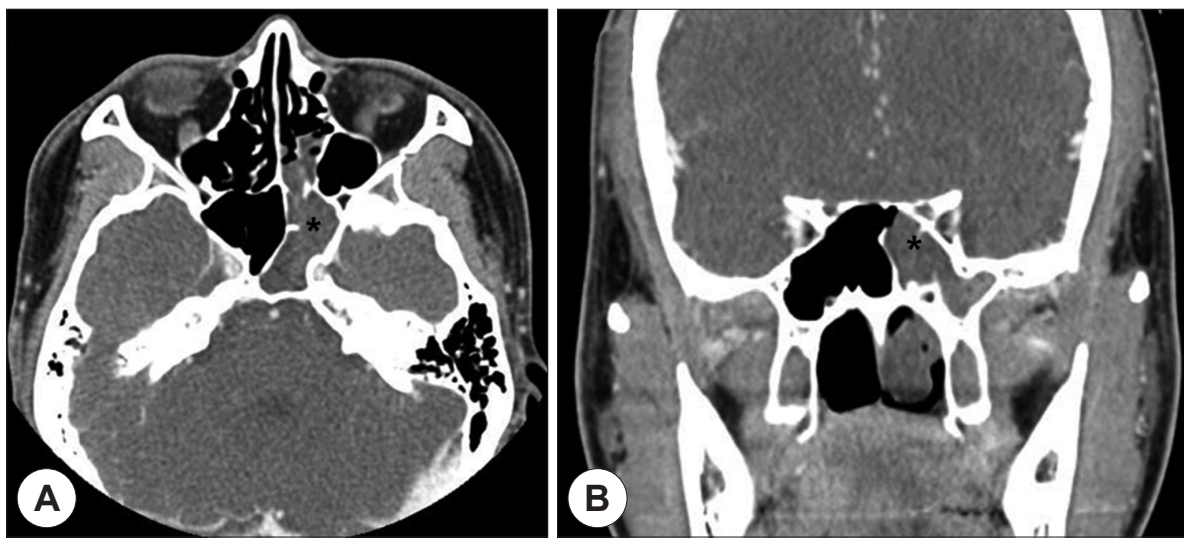

Fig. 2. Computed tomography scan demonstrated non-enhancing bulging mass (asterisk) with soft tissue density in the posterior ethmoid sinus and left sphenoid sinus without the erosion of the sella turcica or adjacent bony wall invasion (A : axial plane, B : coronal plane). 
by bands of spindle cells. At high power view, these chondroid nodules did not demonstrate any cellular atypia or mitotic activities, excluding other malignant cartilaginous tumors. Immunohistochemical staining revealed that the cells within chondroid nodules were positive for S-100 protein and confirmed the presence of chondrocytes. It was negative for pan cytokeratin, smooth muscle actin, desmin, leukocyte common antigen (CD45) and CD56. Based on the histologic findings and results of immunohistochemistry, the nasal polyp was diagnosed as chondromesenchymal hamartoma (Fig. 4).
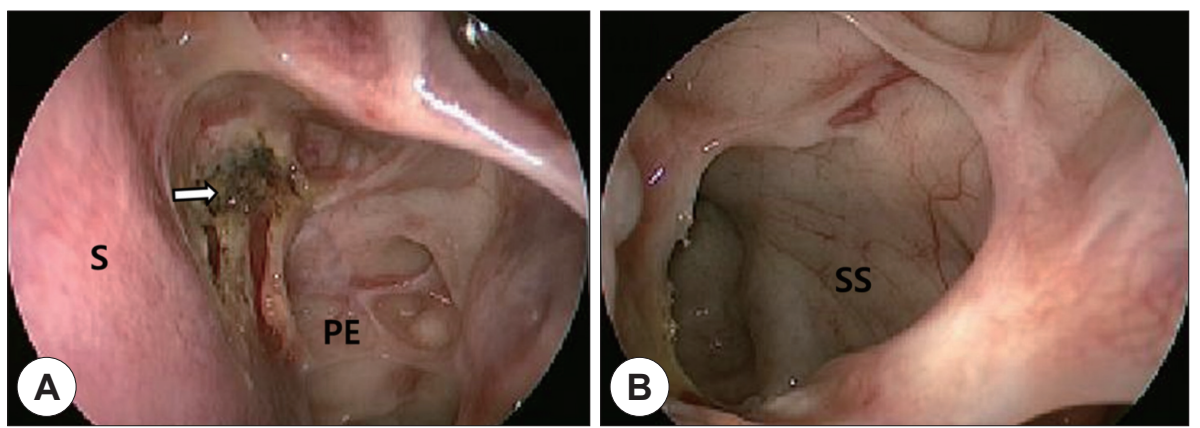

Fig. 3. A : Postreoperative endoscopic view showed drilled tumor attachment site (left superior turbinate, white arrow). B : Postoperative endoscopic view showed another drilled tumor attachment site (left sphenoid sinus septum). S : septum, PE : posterior ethmoid sinus, SS : left sphenoid sinus.
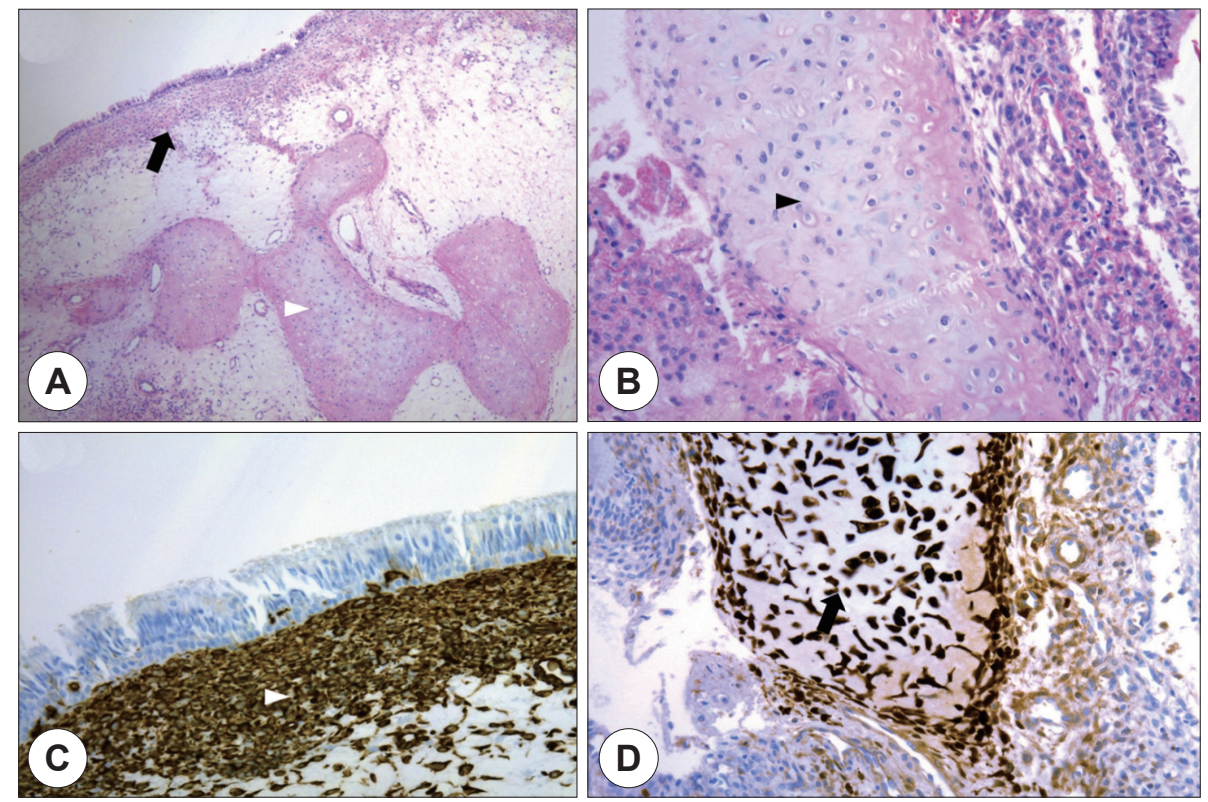

Fig. 4. A : Low power microscopic view shows non-proliferative sinonasal mucosa with subepithelial spindle cell proliferation (black arrow) and islands of cartilage within myxoid stroma (white arrow head). A dense layer of spindle cells abuts an intact sinonasal epithelial surface. (Hematoxylin and Eosin, $\times 100$ ). B : High power microscopic view, the chondroid nodules(black arrow head) do not demonstrate any cellular atypia or mitotic activities (Hematoxylin and Eosin, $\times 400)$. C : The spindle cells forming a subepithelial hypercellular sheet are immunohistochemically positive for vimentin (white arrow head) (Immunohistochemistry for vimentin, $\times 400$ ). D : Immunohistochemical staining for S-100 protein is positive in cartilaginous component (black arrow) (Immunohistochemistry for S-100 protein, $\times 400$ ). 
At present, the patient is free of recurrence for 18 months.

\section{Discussion}

NCMH usually causes nasal obstruction, epistaxis, septal deviation and chronic sinusitis. The presentation and symptoms depend on the size, location of the tumor and involvement of surrounding structures. ${ }^{6}$ Orbital involvement of the tumor can cause proptosis, enophthalmos, or impairment of eye movement. ${ }^{7)}$ Mesenchymal hamartoma was also reported as an intracranial invasion. ${ }^{8)}$ The intracranial extension of the tumor can result in neurological symptoms such as hydrocephalus and oculomotor disturbances. Other symptoms of NCMH include respiratory and feeding difficulties, rhinorrhea, epistaxis, ptosis, visual disturbances, and otitis media. ${ }^{79)}$ Our patient had no ophthalmic, neurologic complaints except only ipsilateral nasal obstruction.

$\mathrm{NCMH}$ of the endoscopic findings may be confused with inflammatory polyps. But, compared to $\mathrm{NCMH}$, inflammatory polyps rarely occur the rear portion of the nasal septum. ${ }^{6}$ Our case showed a sphenochoanal polyp like appearance and location.

Even though several reports suggested that radiological diagnosis of $\mathrm{NCMH}$, in general, the imaging features of this rare tumor, are not specific. ${ }^{5,10,11)}$ The reported CT findings include internal calcifications, bony remodeling, variable enhancement, cystic components, local extension into the orbit, paranasal sinuses and, rarely, intracranial compartment. ${ }^{5,10,12,13)}$ The enhancement pattern of CT is variable, but generally mild, in spite of the presence of vascularity commonly seen on pathology. Magnetic resonance imaging (MRI) characteristic of NCMH include well-defined T2 hyperintense myxoid and cystic components, gradient susceptibility and intrinsic $\mathrm{T} 1$ shortening related to blood products and mineralization, and $\mathrm{T} 2$ hypointensity related to mineralization and fibrosis. While CT better visualizes osseous erosion and remodeling, MRI provides superior tissue characterization and delineation of extension into the adjacent structures. MRI is especially helpful in evaluating intracranial extension and evaluating the involvement of the intraorbital contents. ${ }^{11)}$

The imaging finding reflects the histological finding of NCMH, which is made up of different mesenchymal elements with a focally lobular architecture. ${ }^{10)}$ The main constituents are irregular segments of mature and immature hyaline cartilage with intermittent binucleated chondrocytes. The segments of cartilage are well demarcated from the surrounding stromal tissues, which have a mucous framework and consist of a relatively monotonous and compact spindle cell population with variable cellularity. ${ }^{5,9)}$

The immunohistochemistry features show positivity to smooth muscle actin, S-100, vimentin, KP-1, and Leu-7, on the other hand immunoreactivities for cytokeratin, epithelial membrane antigen, and negativity to desmin. ${ }^{5,14)}$

If the chondroid ingredient is detected in the initial biopsy material, the differential diagnosis is more limited. Chondroid nasal neoplasms are uncommon. As well as NCMH, they include chondromas, chondrosarcomas or chondroblastic osteosarcoma. ${ }^{15)}$ Mesenchymal chondrosarcoma has immunoreactivity for CD99 in undifferentiated small round cells and S-100 protein in chondroid areas, which is similar to our present case. However, spindle mesenchymal cells, not small round cells, in our case with myofibroblastic differentiation and immunostaining positive for SMA are more likely to NCMH. Accordingly, meticulous histological inspection is necessary to accurately diagnose this tumor when it occured in adults. ${ }^{3)}$

Other types of hamartoma also have been reported in the sinonasal region but the only one that might include the differential diagnosis of the current lesion is the condro-osseous respiratory epithelial adenomatoid hamartoma (COREAH). ${ }^{16)}$ Nevertheless, with the absence of the overlying mucosa, no epithelial elements were identified in NCMH. However, according to one report of $\mathrm{NCMH}$, it is possible that COREAH and $\mathrm{NCMH}$ are merely another type of same spectrum of chondro- 
osseous hamartomas rather than distinct entities. ${ }^{9)}$

Currently, the treatment of choice for an $\mathrm{NCMH}$ is complete surgical excision. ${ }^{5,9)}$ If the lesion is restricted in the nasal cavity, it is suitable for endoscopic surgery in many cases. Nevertheless, the infiltrative nature of the lesion can be difficult to obtain clean margins. ${ }^{5)}$ Relapse of an NCMH after operation has been reported in patients with deficient resections or microscopic residue of tumor. ${ }^{7,9)}$ Consequently it is expected that complete resection of the tumor is to be confidently curative. Our case showed recurrence because the tumor was misunderstood as a conventional sphenochoanal polyp at first surgery, so it does not seemed to be a complete resection. The postoperative radiotherapy following incomplete resection has also been reported. ${ }^{8)}$ Because of limited clinical experience, there is the question of how to treat residual or unresectable lesions. ${ }^{10)}$

The typical lesion previously been reported only in the case of young children, according to this case, these lesions may result in a substantially extends the range of age. Therefore, regardless of age, in the case of chondroid proliferations of the nose and paranasal sinuses, NCMH should be considered a differential diagnosis. Because of the malignant potential of $\mathrm{NCMH}$ in adult patients, it is essential for the appropriate immunohistochemical and histological thorough examination.

\section{REFERENCES}

1) Alrawi M, McDermott M, Orr D, Russell J. Nasal chondromesynchymal hamartoma presenting in an adolescent. Int J Pediatr Otorhinolaryngol 2003;67(6):669-72.

2) Li GY, Fan B, Jiao YY. Endonasal endoscopy for removing nasal chondromesenchymal hamartoma extending from the lacrimal sac region. Can J Ophthalmol 2013;48(2):e22-3.

3) Li Y, Yang QX, Tian XT, Li B, Li Z. Malignant transformation of nasal chondromesenchymal hamartoma in adult: a case report and review of the literature. Histol Histopathol
2013;28(3):337-44.

4) Moon SH, Kim MM. Nasal chondromesenchymal hamartoma with incomitant esotropia in an infant: a case report. Can J Ophthalmol 2014;49(1):e30-2.

5) Johnson C, Nagaraj U, Esguerra J, Wasdahl D, Wurzbach D. Nasal chondromesenchymal hamartoma: radiographic and histopathologic analysis of a rare pediatric tumor. Pediatr Radiol 2007;37(1):101-4.

6) Park HS, Choi JW, Koo SK, Song CY. A case of chondroosseous respiratory epithelial adenomatoid hamartoma originated from nasal cavity. J Rhinol 2011;18:151-4.

7) Hsueh C, Hsueh S, Gonzalez-Crussi F, Lee T, Su J. Nasal chondromesenchymal hamartoma in children: report of 2 cases with review of the literature. Arch Pathol Lab Med 2001; 125(3):400-3.

8) Kato K, Ijiri R, Tanaka Y, Hara M, Sekido K. Nasal chondromesenchymal hamartoma of infancy: the first Japanese case report. Pathol Int 1999;49(8):731-6.

9) McDermott MB, Ponder TB, Dehner LP. Nasal chondromesenchymal hamartoma: an upper respiratory tract analogue of the chest wall mesenchymal hamartoma. Am J Surg Pathol 1998;22(4):425-33.

10) Kim JE, Kim HJ, Kim JH, Ko YH, Chung SK. Nasal chondromesenchymal hamartoma: CT and MR imaging findings. Korean J Radiol 2009;10(4):416-9.

11) Yao-Lee A, Ryan M, Rajaram V. Nasal chondromesenchymal hamartoma: correlation of typical MR, CT and pathological findings. Pediatr Radiol 2011;41(5):675-7.

12) Kim B, Park SH, Min HS, Rhee JS, Wang KC. Nasal chondromesenchymal hamartoma of infancy clinically mimicking meningoencephalocele. Pediatr Neurosurg 2004; 40(3):136-40.

13) Ozolek JA, Carrau R, Barnes EL, Hunt JL. Nasal chondromesenchymal hamartoma in older children and adults: series and immunohistochemical analysis. Arch Pathol Lab Med 2005;129(11):1444-50.

14) Kim DW, Low W, Billman G, Wickersham J, Kearns D. Chondroid hamartoma presenting as a neonatal nasal mass. Int J Pediatr Otorhinolaryngol 1999;47(3):253-9.

15) Koka V, Vericel R, Lartigau E, Lusinchi A, Schwaab G. Sarcomas of nasal cavity and paranasal sinuses: chondrosarcoma, osteosarcoma and fibrosarcoma. J Laryngol Otol 1994;108(11):947-53.

16) Shim YS, Park WI, Kim JY, Cho JE. A case of respiratory epithelial adenomatoid hamartoma in nasal septum. $J$ Clinical Otolatyngol 2014;25(2):236-9. 